\title{
SCANNING ELECTRON MICROSCOPY OF THE SURFACE OF THE RAT UTERINE EPITHELIUM DURING DELAYED IMPLANTATION
}

\author{
A. PSYGHOYOS AND P. MANDON
}

\author{
I.N.S.E.R.M., Centre de Recherches de Bicêtre, et \\ Institut de Pathologie Cellulaire, Hôpital de Bicêtre, \\ 94-Bicêtre, France
}

(Received 18th February 1971)

Delayed implantation can be experimentally induced in the rat by various procedures postponing the completion of the progesterone-oestrogen sequence which results in the uterine state of receptivity (Psychoyos, 1967). Thus, in animals ovariectomized early in pregnancy and treated subsequently with progesterone alone, the uterus remains in a 'neutral' state which can be extended to several months, until oestrogen is added to the progesterone treatment. The present paper reports observations obtained by scanning electron stereoscopy on the ultrastructure of the surface of the luminal epithelium during this state.

The endometria used for this study were taken from Wistar-strain rats ovariectomized on the 2nd day of pregnancy and treated daily with $5 \mathrm{mg}$ of progesterone. On the 10th to 12 th day post coitum, laparotomies were performed under ether anaesthesia and uterine samples about $5 \mathrm{~mm}$ in length were removed, fixed in a cold buffered solution of glutaraldehyde, separated into two halves by a longitudinal section through the mesometrial and antimesometrial poles, and then freeze dried and prepared for observation.

In the samples examined, the walls of the uterine lumen were found to be entirely covered with a thick carpet of epithelial microvilli. 'Sea-anemone-like' formations occurred at frequent intervals among them. The microvilli were short and regular, occasionally fusing at their extremities. The 'sea-anemonelike' formations were of various sizes ( 5 to $12 \mu$ ) and each one appeared to consist of numerous, thin, long and regular, or flat and irregular tentacles, which were usually coiled. The tentacles were formed by and projected from a basal body.

Occasionally, the tentacles appeared completely flattened, forming a circular compact mass with a hollow centre. Such 'opened' formations were found together with closed ones, so it is unlikely that the 'opening' was an artifact of the fixation. The different shapes, ranging from the closed bunch to the opened type, seemed rather to correspond to various degrees of development.

These observations confirm those made using the transmission electron microscope. In rats ovariectomized early in pregnancy and treated with 
progesterone alone, Potts \& Psychoyos (1967) and Nilsson (1970) have already described regular epithelial microvilli of about $0.3 \times 0.1 \mu$ which project into the uterine lumen. Scanning electron stereoscopy has under these hormonal conditions revealed, in addition, the existence of what we have called here 'sea-anemone-like' formations. These formations should correspond to the cytoplasmic protrusions observed by electron transmission in sections of the luminal surface of epithelial cells. The three-dimensional observations offered by the scanning electron microscope show clearly the organized nature of these formations. This organization prompts a consideration of such formations as cellular organelles with precise functions, the significance of which should be of importance in the composition of the uterine milieu surrounding the dormant blastocyst.

A. P. wishes to express his deep gratitude to Professor Bessis for so kindly providing the excellent facilities of the Institut de Pathologie Cellulaire.

\section{REFERENCES}

Nitson, O. (1970) Some ultrastructural aspects of ovo-implantation. In: Ovo-Implantation, Human Gonadotropins and Prolactin, p. 52. Karger, Basel.

Potrs, M. \& Psychoyos, A. (1967) Evolution de l'ultrastructure des relations ovo-endometriales sous l'influence de l'oestrogène, chez la ratte en retard expérimental de nidation. C.r. hebd. Séanc. Acad. Sci., Paris, 264, 370.

Psychoyos, A. (1967) The hormonal interplay controlling egg-implantation in the rat. Adv. reprod. Physiol. 2, 257. 

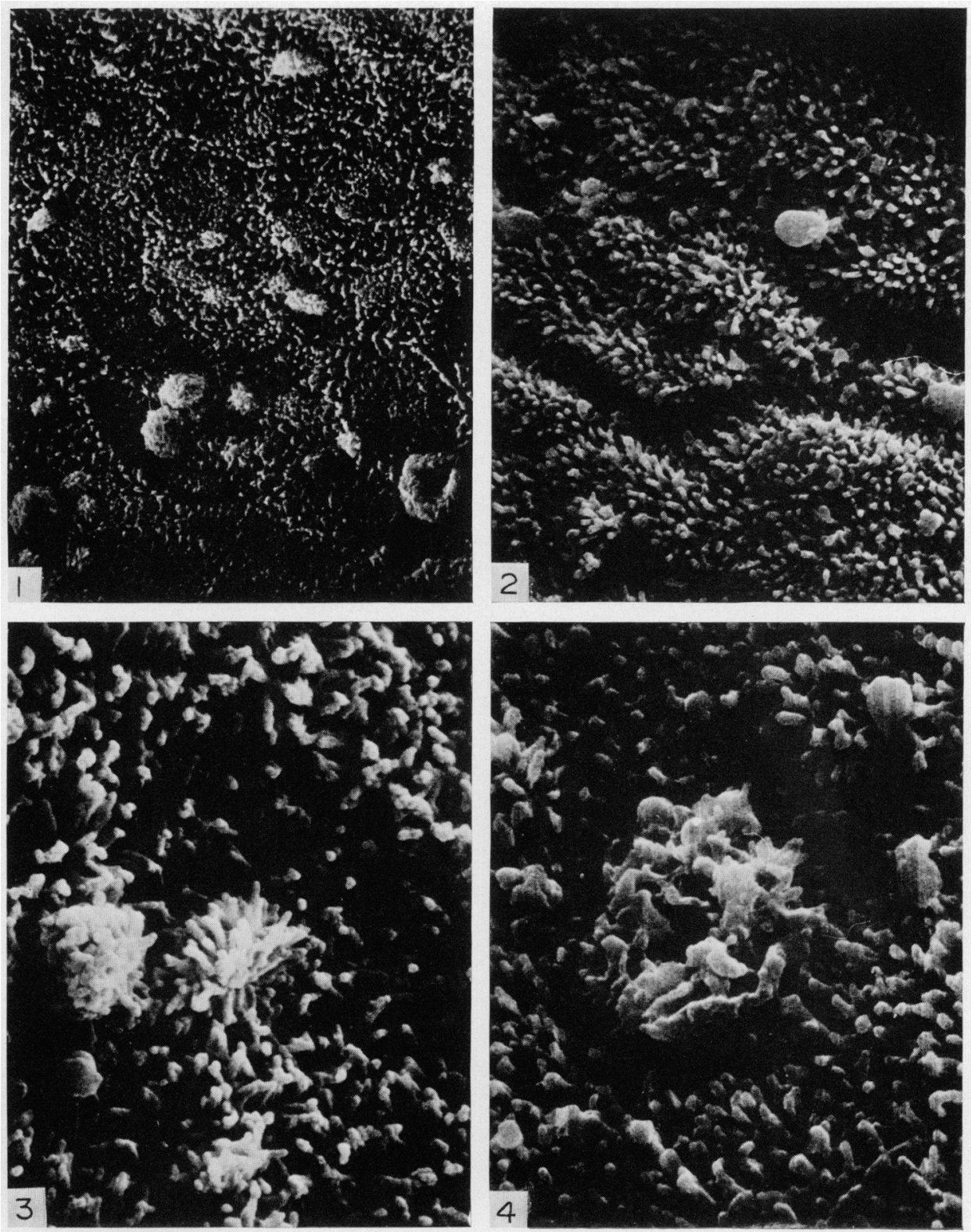

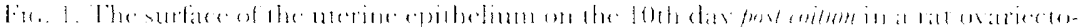

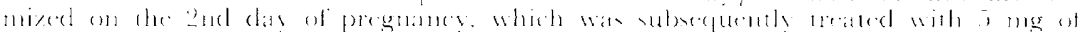

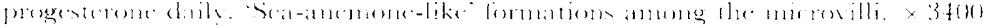

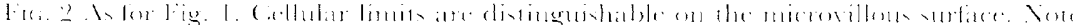

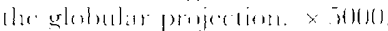

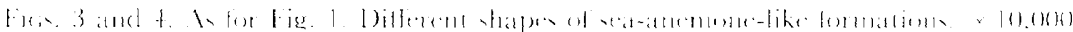

